\title{
Effects of duration of moderate increases in grain feeding on endotoxins in the digestive tract and acute phase proteins in peripheral blood of yearling calves
}

\author{
J. C. Plaizier, ${ }^{* 1}$ S. Li, ${ }^{*}$ M. Le Sciellour, ${ }^{*}$ B. L. Schurmann,† P. Górka,ł and G. B. Penner† \\ *University of Manitoba, Winnipeg, Canada, R3R 3N2 \\ †Department of Animal and Poultry Science, University of Saskatchewan, Saskatoon, Canada, S7N 5A8 \\ fDepartment of Animal Nutrition and Feed Management, University of Agriculture in Krakow, al. Mickiewicza 24/28, 30-059 Krakow, Poland
}

\begin{abstract}
Effects of duration of grain feeding on the concentration of endotoxic lipopolysaccharide (LPS) in digesta throughout the digestive tract and on acute phase proteins and LPS in peripheral blood were determined in Holstein yearling calves. Twenty-five Holstein yearling steer calves received either a forage-based diet containing $92 \%$ hay and $8 \%$ of a mineral and vitamin pellet on a dry matter basis (CON) or a moderate-grain diet, obtained by replacing $41.5 \%$ of the hay in the foragebased diet with barley grain, for 3 (MG3), 7 (MG7), 14 (MG14), or $21 \mathrm{~d}$ (MG21) before slaughter. Immediately before slaughter, blood samples were collected from the jugular vein. Immediately after slaughter, digesta samples were collected from the rumen, jejunum, ileum, cecum, colon, and rectum. Rumen liquid digesta, digesta from the intestines, and peripheral blood plasma were analyzed for LPS. Peripheral blood plasma and serum were analyzed for the acute phase proteins amyloid A, haptoglobin, and LPS-binding protein. Feeding the grain diet increased the LPS concentration in rumen fluid linearly from 15,488 endotoxin units $(\mathrm{EU}) / \mathrm{mL}$ for CON to $70,146 \mathrm{EU} / \mathrm{mL}$ for MG7. Concentrations of LPS in rumen fluid in MG14 and MG21 were 61,944 and 56,234 EU/mL, respectively, and did not differ. The LPS concentrations in jejunal digesta were much lower than that in digesta elsewhere in the digestive tract, which suggests that ruminal LPS is broken down in the abomasum or proximal jejunum. The concentration of digesta LPS in the ileum was higher than that of digesta elsewhere in the intestines and similar to that in rumen fluid. The duration of grain feeding increased the LPS concentration in digesta in the ileum and cecum and tended to increase that in the colon cubically. Concentrations of LPS in this part of the digestive tract were highest in the MG3 and MG21 groups. The
\end{abstract}

Received March 21, 2014

Accepted July 27, 2014.

${ }^{1}$ Corresponding author: Plaizier@umanitoba.ca highest concentrations of LPS in digesta in the cecum, colon, and rectum were 3.7, 3.8, and 5.6 times higher than that in CON, respectively. Grain feeding and the increase in LPS in digesta were not accompanied by an acute phase response or a detectable concentration of LPS in peripheral blood. The absence of LPS in peripheral blood and the lack of increase in acute phase proteins indicated that the grain feeding protocol used in the current study and the accompanying changes in LPS concentrations of the digesta did not result in systemic inflammation.

Key words: calf, grain, digestive tract, lipopolysaccharide

\section{INTRODUCTION}

To meet the nutrient requirements of high-yielding dairy cows and beef cattle, energy-dense diets have to be fed (Plaizier et al., 2008). These energy-dense diets are primarily obtained with moderate to high inclusion rates of grain. However, these types of diets can affect cattle health, as increases in grain feeding have been associated with a heightened risk for SARA, increased concentrations of endotoxic LPS in the gut, as well as increased concentrations of acute phase proteins in peripheral blood (Gozho et al., 2007; Emmanuel et al., 2008; Li et al., 2012b).

Lipopolysaccharide is a component of the outer membrane of gram-negative bacteria that can be shed during bacterial growth or released following cell disintegration and lysis (Hurley, 1995; Wells and Russell, 1996b). The increase in acute phase proteins, also referred to as an acute phase response, could be caused by the translocation of LPS from the digestive tract into the peripheral circulation (Emmanuel et al., 2008; Plaizier et al., 2012).

Gozho et al. (2007), Emmanuel et al. (2008), Khafipour et al. (2009b), and Li et al. (2012b) reported that increased grain feeding increased the concentration of LPS in rumen and cecal digesta, and the concentration of acute phase proteins in peripheral blood. Increasing 
grain inclusion to induce SARA in dairy cows results in major changes in the microbiota of rumen digesta, including increases in starch- and soluble sugar-fermenting bacteria, lactic acid-fermenting bacteria, and Escherichia coli, as well as a reduction in the population of gram-negative Bacteroidetes (Nagaraja and Titgemeyer, 2007; Khafipour et al., 2009c). Although most studies use a short-term or transient increase in the concentration of grain in the diet to induce SARA, it is clear that microbial adaptation (Tajima et al., 2000) and physiological adaptation of the rumen are incomplete (Schurmann, 2013). The duration of time that cattle are fed highly fermentable diets may affect the response of microbiota and, therefore, LPS, in the digestive tract (Nagaraja and Titgemeyer, 2007). Increased concentrations of LPS in digesta may directly compromise the barrier function of the epithelium, but this effect may be both concentration and time dependent (Chin et al., 2006). Therefore, this effect may not be observed in a mild episode of SARA for a few hours or a few days (Khafipour et al., 2009b; Penner et al., 2010; Li et al., 2012b). In contrast, evidence suggests that prolonged increases in grain feeding may cause epithelia of the digestive tract of cattle to adapt, enhancing epithelial barrier function (Lodemann and Martens, 2006). Although the increase in LPS in the rumen (Nagaraja et al., 1978; Gozho et al., 2007) and in the hindgut (Li et al., 2012b) due to high-grain diets has been confirmed repeatedly, there is little information about such increases in other sites of the digestive tract, such as the jejunum and ileum.

The objectives of this study were to determine (1) the effects of the duration of feeding a moderate level of grain on LPS in digesta in the rumen, small intestine, large intestine, and rectum of yearling calves; and (2) whether these durations are accompanied by increases in acute phase proteins and LPS in peripheral blood.

\section{MATERIALS AND METHODS}

\section{Animals, Diets, and Experimental Procedures}

The experimental design and the management of feeding of the animals were described in detail in Schurmann (2013). In summary, 25 Holstein bull calves (BW of $213 \pm 23 \mathrm{~kg}$, mean $\pm \mathrm{SD}$, approximately 5 to 7 mo of age) were blocked into 5 groups based on age and BW. At the start of the study, all calves were group-housed and fed a forage-based diet containing $91.5 \%$ hay and $8.5 \%$ of a mineral and vitamin pellet on a DM basis for at least $5 \mathrm{wk}$. One of 5 calves in each of 5 blocks was slaughtered (control, $\mathbf{C O N} ; \mathrm{n}=5$ ) before the day on which the rest of the calves were moved into individual barns and their diet was abruptly switched to a moderate-grain (MG) diet obtained by replacing $41.5 \%$ of the hay in the forage-based diet with barley grain. One calf in each block was then slaughtered on d 3 (MG3; n = 5), d 7 (MG7; n = 5), d 14 (MG14; $\mathrm{n}=5$ ), or $\mathrm{d} 21$ (MG21; $\mathrm{n}=5$ ) after beginning the MG diet. The chemical composition of the CON diet as reported by Schurmann (2013) was $87.3 \%$ DM with contents of $\mathrm{CP}, \mathrm{NDF}, \mathrm{ADF}, \mathrm{OM}$, and starch of 10.6, $48.4,33.3,92.1$, and $4.1 \%$ of DM, respectively, and the composition of the MG diet was $87.9 \%$ DM, with contents of CP, NDF, ADF, OM, and starch of 11.4, 33.5, $20.9,93.6$, and $24.6 \%$ of DM, respectively. Both diets were fed in individual mangers once daily at $0800 \mathrm{~h}$ at $2.25 \%$ of BW. The calves were cared for in accordance with the Canadian Council for Animal Care guidelines (CCAC, 1993). All experimental procedures were preapproved by the University of Saskatchewan Animal Research Ethics Board (protocol 20100021).

\section{Slaughter and Sample Collection}

Calves were killed by captive bolt stunning followed by pithing and exsanguination $2 \mathrm{~h}$ after morning feed delivery. At slaughter, samples of digesta were collected from the rumen, jejunum, ileum, cecum, colon, and rectum. The digesta from the reticulorumen was emptied into a plastic basin and mixed thoroughly. Approximately $500 \mathrm{~mL}$ of the digesta was then collected and strained thorough 4 layers of cheesecloth to obtain a representative sample of rumen fluid. Subsequently, approximately $40 \mathrm{~mL}$ of rumen fluid was transferred into $50 \mathrm{~mL}$ sterile tubes, kept on ice, and transported to the laboratory for further processing, as described by Gozho et al. (2005) and Li et al. (2012b). Briefly, sample processing consisted of centrifugation at $4^{\circ} \mathrm{C}$ at 10,000 $\times g$ for $45 \mathrm{~min}$ and aspiration of the supernatant. The supernatant was filtered through a $0.22-\mu \mathrm{m}$ LPS-free filter (Z359904, Sigma, St. Louis, MO). Subsequently, samples were stored in depyrogenated glass tubes at $-20^{\circ} \mathrm{C}$ for subsequent LPS analysis.

Digesta samples from the jejunum, ileum, and colon were collected from a $20-\mathrm{cm}$ intestinal segment, which ended at $2 \mathrm{~m}$ from the duodenum, $20 \mathrm{~cm}$ from the ileo-cecal junction, and the middle of the spiral colon, respectively. Intestinal segments were dissected and the digesta inside of each segment were collected. To collect digesta samples from the cecum and rectum, an approximately 5 -cm-long incision was made at the most distal region of the sac and $10 \mathrm{~cm}$ from the anus, respectively. Digesta were then collected with a sterile spatula and put on ice before processing as described by $\mathrm{Li}$ et al. (2012b). Briefly, processing consisted of mixing $20 \mathrm{~g}$ of digesta sample with an equal amount of physiological saline $(0.90 \% \mathrm{wt} / \mathrm{vol}$ of $\mathrm{NaCl})$. Sub- 
sequently, the mixtures were centrifuged at 3,000 $\times g$ for $15 \mathrm{~min}$ at $4^{\circ} \mathrm{C}$, and the supernatants were stored at $-20^{\circ} \mathrm{C}$ until analyzed for VFA and ammonia nitrogen. Additionally, $10 \mathrm{~g}$ of each sample was transferred into pyrogen-free tubes and mixed with $10 \mathrm{~mL}$ of physiological saline. Samples were then processed for LPS analysis as described earlier for rumen fluid samples.

Blood samples were taken from the jugular vein immediately before slaughter, and collected into two 10$\mathrm{mL}$ evacuated tubes coated with freeze-dried sodium heparin (158 IU) and silicone-coated, clot-activating Vacutainer tubes (BD, Franklin Lakes, NJ) for plasma and serum, respectively. Samples were immediately placed on ice until being centrifuged at 1,800 $\times g$ for 15 min at $4^{\circ} \mathrm{C}$ to harvest plasma and serum. An aliquot of the plasma was transferred to pyrogen-free glass tubes and stored at $-20^{\circ} \mathrm{C}$ for LPS analysis. The remainder of the plasma and serum was divided into $2-\mathrm{mL}$ aliquots and stored at $-20^{\circ} \mathrm{C}$ for further analysis.

\section{Analyses of Digesta}

Rumen fluid, intestinal digesta and rectal contents were analyzed for LPS with a chromogenic kinetic limulus amebocyte lysate (LAL) assay (Kinetic-QCL, Lonza Group Ltd., Basel, Switzerland) using a 50\% $\beta$-glucan blocker (cat. no. N190, Lonza Group Ltd.), as described by Khafipour et al. (2009b) and Li et al. (2012b). The LPS concentrations in intestinal digesta and rectal contents were expressed as endotoxin units (EU) per gram of wet sample. Ammonia nitrogen was analyzed using a colorimetric technique as described by Novozamsky et al. (1974) and Bhandari et al. (2007). Gas chromatography (model 3900 Star, Varian, Walnut Creek, CA) was used for the analyses of VFA, as described by Bhandari et al. (2007).

\section{Analyses of Plasma and Serum Samples}

After thawing, plasma samples were diluted 1:500 with distilled water, and analyzed for serum amyloid A (SAA) using a commercial kit (Tridelta Phase range kit TP-801, Tri-Delta Diagnostics Inc., Morris Plains, NJ) and LPS-binding protein (LBP) using another commercial kit (HK503 kit, Hycult Biotech, Uden, the Netherlands) as described by Gozho et al. (2007) and Khafipour et al. (2009b). A commercial kit was also used for the analysis of haptoglobin $(\mathbf{H p})$ in diluted (1/500) serum (Tridelta Phase kit TP-802, Tri-Delta Diagnostics Inc.) as described by Gozho et al. (2007) and Khafipour et al. (2009b).

Plasma was also analyzed for LPS using a chromogenic kinetic LAL assay (Kinetic-QCL) as described by Li et al. (2012b). The endotoxin standard included with the LAL assay kit used in the current study was extracted from Escherichia coli O55:B5 and had a ratio of reference standard endotoxins to control standard endotoxins (RSE:CSE) of $14 \mathrm{EU} / \mathrm{ng}$. Before analysis, thawed plasma samples were mixed by vortex, diluted 1:3 with LAL reagent water (cat. no. W50-500, Lonza Group Ltd.), and further diluted 1:8 with $10 \mathrm{mM} \mathrm{MgCl}$ solution (cat. no. S50-641, Lonza Group Ltd.). Subsequently, $50 \mu \mathrm{L}$ of Pyrosperse dispersing agent (cat. no. N188, Lonza Group Ltd.) was added to $1.0 \mathrm{~mL}$ of plasma sample dilution so that the resulting concentration of Pyrosperse was 1:200 (vol:vol). The minimum detection level of LPS in plasma was $0.14 \mathrm{EU} / \mathrm{mL}$.

\section{Statistical Analyses}

Data were analyzed as a randomized complete block design with polynomial contrasts used to evaluate whether treatment resulted in linear, quadratic, or cubic patterns using the Mixed Procedure of SAS (version 9.3; SAS Institute Inc., Cary, NC). The model included duration of feeding the MG diet, sampling site in gastrointestinal tract, and their interaction as fixed effects, and block as random effect. Sampling site was treated as repeated measurement. For testing LPS in digesta samples and LPS and acute phase proteins in blood, logarithm transformation was applied to achieve normality of the residuals of the mixed models. The effects were considered significant at $P<0.05$, and trends were discussed at $0.05<P<0.10$.

\section{RESULTS AND DISCUSSION}

The interaction between the duration of feeding the MG diet and the location in the digestive tract on LPS concentrations in the digesta was significant because the effect of duration of feeding the MG diet on LPS concentrations at different sites in the digestive tract varied (Table 1). Feeding the grain diet increased ruminal LPS from 15,488 EU/mL for CON to $70,146 \mathrm{EU} / \mathrm{ml}$ for MG7. Longer grain feeding did not further increase rumen LPS. The concentrations of LPS in rumen fluid during the grain feeding period in our experiment were greater than those observed when feeding of diets with similar grain and fiber contents in the studies by Gozho et al. (2007), Khafipour et al. (2009b), and Li et al. (2012b). However, the LPS concentrations in rumen fluid during the SARA challenges conducted by Gozho et al. (2007), Khafipour et al. (2009b), and Li et al. (2012b) were higher than those observed during the grain feeding period in our study. This may be explained by the lower grain content of the MG diet in the current study compared with that of the SARA challenge diets in the earlier studies. In agreement, the parallel 
study by Schurmann (2013) showed that the duration of feeding the MG diet did not affect the concentration of total VFA in the rumen. This concentration was $84.1 \mathrm{mM}$ across treatments, which is much lower than those observed during the SARA challenges conducted by Gozho et al. (2007), Khafipour et al. (2009b), and Li et al. (2012b). Schurmann (2013) also showed that the mean reticular $\mathrm{pH}$ decreased only from 6.90 for CON to 6.59 for MG7, and increased thereafter to 6.79. This suggests that increasing the dietary grain content increases the LPS concentration of rumen digesta, even if this increase does not induce SARA. Similar observations were reported by Emmanuel et al. (2008) and Zebeli and Ametaj (2009). Moreover, the increase in rumen LPS resulting from feeding the MG diet continued for up to $21 \mathrm{~d}$ after the first grain feeding. This increase does not indicate that the total population of gramnegative bacteria in the rumen changed, as the size of this population and the concentration of LPS in the rumen may not be correlated (Nagaraja et al., 1978). Rather, the increase in grain content in the diets might have increased the turnover rate of gram-negative bacteria and, as a result, the release of LPS (Hurley, 1995; Wells and Russell, 1996a).

The LPS concentration in the jejunum was lower $(P$ $<0.05)$ than that in the rumen, ileum, cecum, colon, or rectum (Table 1). Although the LPS concentration in the rumen increased (cubic $P=0.03$ ) due to the MG diet, a linear reduction of LPS in the jejunum $(P$ $=0.05$ ) accompanied by a linear reduction of total VFA $(P=0.04)$ and a tendency for a linear decrease in acetate $(P=0.07)$ were observed in the jejunum with increasing duration of the moderate grain diet (Tables 2 and 3). Digesta flowing out of the reticulo-rumen contains LPS. The reduction in LPS concentration in the jejunal digesta may be due to LPS clearance, neutralization, or detoxification occurring between 2 sampling sites (Mani et al., 2013). Various proteases, lysozyme, and bile acids are involved in this process (Poelstra et al., 1997; Lallès, 2010; Mani et al., 2012). Ribeiro et al. (2010) concluded that acidification, such as that occurring in the abomasum of cattle, deactivates LPS. Alkaline phosphatase, which is a common hydrolase enzyme present in liver and intestine, especially the proximal segment of the intestine, can also dephosphorylate bacterial LPS (Poelstra et al., 1997; Lallès, 2010; Mani et al., 2012). Le Huerou et al. (1992) indicated that alkaline phosphatase activity is located mainly in the proximal jejunum and is nearly absent in the distal jejunum and the ileum of growing cattle. In rodents, alkaline phosphatase mRNA and activity are present at their highest levels in the duodenum and decrease sharply toward the jejunum and ileum (Lallès, 2010). Therefore, we can speculate that alkaline phosphatase in the bovine proximal jejunum plays a significant role in dephosphorylating bacterial LPS and reducing its toxicity. The tendency for a linear reduction in LPS in jejunal digesta observed with advancing days on the MG diet in our study may indicate that the capacity of LPS detoxification before the jejunum increased when the calves were fed the MG diet for an extended period. As this is the first study in which ruminal and jejunal LPS were compared, further studies are needed to shed more light on this issue.

The concentration of LPS in the digesta collected at the distal ileum was higher $(P<0.05)$ than that in the jejunum, cecum, colon, or rectum, and was similar to that observed in the rumen (Table 1). The effect of feeding the MG diet to calves on LPS concentration in the ileal digesta showed a cubic pattern of change, increasing for MG3 and MG7, decreasing for MG14, and increasing once again for MG21 (Table 1). The duration of time feeding the moderate grain diet did not affect the profile of VFA and tended to decrease ammonia nitrogen concentration cubically in the ileum.

The concentration of LPS in the digesta in the jejunum was lower than that in the rumen and ileum (Table 1). Therefore, LPS in the ileum must be mainly derived

Table 1. Effects of the duration of feeding a moderate-grain diet on LPS in rumen fluid $\left[\log _{10}(\mathrm{EU} / \mathrm{mL})\right]$ and intestine $\left[\log _{10}(\mathrm{EU} / \mathrm{g}\right.$ of wet digesta $\left.)\right]$ of calves

\begin{tabular}{|c|c|c|c|c|c|c|c|c|c|}
\hline \multirow[b]{2}{*}{ Compartment } & \multicolumn{5}{|c|}{ Treatment $^{1}$} & \multirow[b]{2}{*}{$\mathrm{SE}$} & \multicolumn{3}{|c|}{ Contrast $^{2}$} \\
\hline & $\mathrm{CON}$ & MG3 & MG7 & MG14 & MG21 & & $\mathrm{L}$ & $\mathrm{Q}$ & $\mathrm{C}$ \\
\hline Rumen & 4.19 & 4.69 & 4.85 & 4.79 & 4.75 & 0.10 & $<0.01$ & $<0.01$ & 0.03 \\
\hline Jejunum & 3.40 & 3.38 & 3.36 & 3.40 & 2.82 & 0.19 & 0.05 & 0.16 & 0.40 \\
\hline Ileum & 4.58 & 5.03 & 4.76 & 4.49 & 4.84 & 0.13 & 0.85 & 0.62 & 0.01 \\
\hline Cecum & 3.52 & 4.15 & 3.96 & 3.65 & 4.09 & 0.22 & 0.39 & 0.93 & 0.02 \\
\hline Colon & 3.46 & 3.96 & 3.66 & 3.50 & 4.03 & 0.25 & 0.36 & 0.53 & 0.10 \\
\hline Rectum & 3.22 & 3.73 & 3.65 & 3.19 & 3.96 & 0.22 & 0.22 & 0.51 & 0.02 \\
\hline
\end{tabular}

${ }^{1}$ Control (CON) calves received $91.5 \%$ chopped hay and $8.5 \%$ vitamin-mineral supplement. Calves assigned to MG3, MG7, MG14, and MG21 received a high-energy (moderate-grain) diet consisting of $41.5 \%$ barley grain, $50 \%$ chopped hay, and $8.5 \%$ vitamin-mineral supplement for 3, 7, 14, and $21 \mathrm{~d}$, respectively.

${ }^{2}$ Contrast patterns: $\mathrm{L}=$ linear, $\mathrm{Q}=$ quadratic, $\mathrm{C}=$ cubic. 
Table 2. Effects of the duration of feeding a moderate-grain diet on total VFA concentration ( $\mathrm{m} M$ ) of digesta in the intestines of calves

\begin{tabular}{|c|c|c|c|c|c|c|c|c|c|}
\hline \multirow[b]{2}{*}{ Compartment } & \multicolumn{5}{|c|}{ Treatment $^{1}$} & \multirow[b]{2}{*}{$\mathrm{SE}$} & \multicolumn{3}{|c|}{ Contrast $^{2}$} \\
\hline & $\mathrm{CON}$ & MG3 & MG7 & MG14 & MG21 & & $\mathrm{L}$ & $\mathrm{Q}$ & $\mathrm{C}$ \\
\hline Jejunum & 12.0 & 7.9 & 9.8 & 7.6 & 8.1 & 1.4 & 0.04 & 0.20 & 0.55 \\
\hline Ileum & 21.0 & 25.1 & 21.8 & 21.0 & 22.7 & 2.9 & 0.89 & 0.92 & 0.36 \\
\hline Cecum & 104.9 & 107.6 & 113.9 & 122.1 & 118.5 & 7.9 & 0.13 & 0.44 & 0.70 \\
\hline Colon & 76.6 & 96.3 & 98.3 & 97.0 & 109.9 & 6.8 & 0.01 & 0.48 & 0.10 \\
\hline Rectum & 61.3 & 88.1 & 94.5 & 80.3 & 103.1 & 7.4 & 0.01 & 0.44 & 0.01 \\
\hline
\end{tabular}

${ }^{1}$ Control (CON) calves received $91.5 \%$ chopped hay and $8.5 \%$ vitamin-mineral supplement. Calves assigned to MG3, MG7, MG14, and MG21 received a high-energy (moderate-grain) diet consisting of $41.5 \%$ barley grain, $50 \%$ chopped hay, and $8.5 \%$ vitamin-mineral supplement for 3, 7, 14, and $21 \mathrm{~d}$, respectively.

${ }^{2}$ Contrast patterns: $\mathrm{L}=$ linear, $\mathrm{Q}=$ quadratic, $\mathrm{C}=$ cubic.

from local gram-negative bacteria. Assuming a stable ratio of viable bacterial count and endotoxin concentration during normal growth of gram-negative bacteria as reported by Dofferhoff et al. (1991), the higher LPS in ileal digesta might indicate a larger population of gram-negative bacteria species in the ileum than in the large intestine. For instance, Maki and Picard (1965) reported that the population of $E$. coli, a gram-negative species that sheds high potency LPS, was numerically larger in the ileum than that in the cecum and colon of cattle. However, another explanation could be that the release rates of endotoxin from gram-negative bacteria in the ileum and large intestine are different. This agrees with Goris et al. (1988), who reported that the concentration of LPS in intestinal digesta of mice corresponds with the proliferative activity of gram-negative bacteria but not necessarily with their population.

A drastic reduction of the LPS concentration in the digesta from the ileum to the cecum was detected in our study. Because the ileal samples in our study were collected in the region before the incision located $20 \mathrm{~cm}$ from the ileo-cecal junction, detoxification, and possibly translocation, of LPS in the distal ileum may have contributed to this reduction. In addition, microfold cells, a type of specialized lymphoid cells in Peyer's patches, and dendritic cells in the distal ileum can actively transport foreign antigens, including endotoxins, from the intestine to underlying macrophages (Neutra et al., 1996; Rescigno et al., 2001), in which LPS is bound, internalized, and partially degraded (Hampton et al., 1991).

The concentrations of LPS in the digesta collected in the cecum, colon, and rectum were higher than that in the jejunum, but lower than that in the rumen and ileum (Table 1). No difference was detected among the concentrations of LPS in the cecum, colon, and rectum (Table 1). The effect of the MG diet on LPS concentration in the cecal digesta and rectal contents showed a cubic pattern of change, slightly increasing for MG3 and MG7, then decreasing for MG14, before increasing for MG21 (Table 1). A tendency for a similar cubical pattern for LPS concentration was detected in colon digesta (Table 1). The duration of feeding the MG diet increased only butyrate in the cecum, linearly. In contrast, feeding the grain diet to calves had a much greater effect on hindgut fermentation, as indicated by linearly increased concentrations of total VFA, acetate, propionate, and butyrate in digesta of the colon and rectum (Tables 2, 3, 4 and 5, respectively). The grain diet reduced the ammonia nitrogen concentration of

Table 3. Effects of the duration of feeding a moderate-grain diet on the acetate concentration of digesta $(\mathrm{m} M)$ in the intestines of calves

\begin{tabular}{|c|c|c|c|c|c|c|c|c|c|}
\hline \multirow[b]{2}{*}{ Compartment } & \multicolumn{5}{|c|}{ Treatment $^{1}$} & \multirow[b]{2}{*}{$\mathrm{SE}$} & \multicolumn{3}{|c|}{ Contrast $^{2}$} \\
\hline & $\mathrm{CON}$ & MG3 & MG7 & MG14 & MG21 & & $\mathrm{L}$ & $\mathrm{Q}$ & $\mathrm{C}$ \\
\hline Jejunum & 7.5 & 3.7 & 5.5 & 3.8 & 4.0 & 1.3 & 0.07 & 0.26 & 0.39 \\
\hline Ileum & 17.5 & 21.9 & 19.3 & 18.5 & 20.0 & 2.4 & 0.92 & 0.91 & 0.27 \\
\hline Cecum & 78.6 & 82.6 & 87.8 & 93.9 & 90.2 & 6.2 & 0.12 & 0.32 & 0.79 \\
\hline Colon & 55.0 & 72.7 & 74.3 & 73.9 & 83.7 & 5.5 & 0.01 & 0.36 & 0.09 \\
\hline Rectum & 46.5 & 67.3 & 71.1 & 60.2 & 76.5 & 5.4 & 0.01 & 0.40 & $<0.01$ \\
\hline
\end{tabular}

${ }^{1}$ Control (CON) calves received $91.5 \%$ chopped hay and $8.5 \%$ vitamin-mineral supplement. Calves assigned to MG3, MG7, MG14, and MG21 received a high-energy (moderate-grain) diet consisting of $41.5 \%$ barley grain, $50 \%$ chopped hay, and $8.5 \%$ vitamin-mineral supplement for $3,7,14$, and $21 \mathrm{~d}$, respectively.

${ }^{2}$ Contrast patterns: $\mathrm{L}=$ linear, $\mathrm{Q}=$ quadratic, $\mathrm{C}=$ cubic. 
Table 4. Effects of the duration of feeding a moderate-grain diet on the propionate concentration $(\mathrm{m} M)$ of digesta in the intestines of calves

\begin{tabular}{|c|c|c|c|c|c|c|c|c|c|}
\hline \multirow[b]{2}{*}{ Compartment } & \multicolumn{5}{|c|}{ Treatment $^{1}$} & \multirow[b]{2}{*}{$\mathrm{SE}$} & \multicolumn{3}{|c|}{ Contrast $^{2}$} \\
\hline & $\mathrm{CON}$ & MG3 & MG7 & MG14 & MG21 & & $\mathrm{L}$ & $\mathrm{Q}$ & $\mathrm{C}$ \\
\hline Jejunum & 0.89 & 0.54 & 0.71 & 0.56 & 0.58 & 0.15 & 0.18 & 0.41 & 0.51 \\
\hline Ileum & 1.17 & 1.15 & 1.02 & 0.82 & 1.00 & 0.19 & 0.25 & 0.33 & 0.49 \\
\hline Cecum & 16.21 & 15.90 & 16.81 & 18.16 & 17.88 & 1.07 & 0.11 & 0.70 & 0.49 \\
\hline Colon & 11.63 & 13.93 & 13.94 & 13.90 & 16.07 & 0.75 & $<0.01$ & 0.87 & 0.06 \\
\hline Rectum & 8.54 & 11.26 & 11.78 & 10.30 & 13.91 & 1.07 & 0.01 & 0.90 & 0.02 \\
\hline
\end{tabular}

${ }^{1}$ Control (CON) calves received $91.5 \%$ chopped hay and $8.5 \%$ vitamin-mineral supplement. Calves assigned to MG3, MG7, MG14, and MG21 received a high-energy (moderate-grain) diet consisting of $41.5 \%$ barley grain, $50 \%$ chopped hay, and $8.5 \%$ vitamin-mineral supplement for 3, 7, 14, and $21 \mathrm{~d}$, respectively.

${ }^{2}$ Contrast patterns: $\mathrm{L}=$ linear, $\mathrm{Q}=$ quadratic, $\mathrm{C}=$ cubic.

cecal and colon digesta cubically and tended to reduce that of rectal contents cubically (Table 6).

Published data on LPS concentration in the large intestine of cattle are sparse. Li et al. (2012a,b,c) reported that LPS in the cecum and rectum of dairy cows ranged from 12,832 to $118,522 \mathrm{EU} / \mathrm{g}$ of wet sample, which is higher than that observed in our study. Moreover, those authors observed a significant increase in LPS in the large intestine when the grain content in the diet increased and SARA was induced. This discrepancy might be explained by different dietary formulations and feeding management in these studies. In the present study, the control diet contained little grain, and the MG diet contained $41.5 \%$ grain, as it was not aimed at inducing SARA. In contrast, the control diets in Li et al. (2012a,b) contained $42 \%$ and $30 \%$ grain, and the high-grain diets for inducing SARA in these studies contained $49 \%$ and $64 \%$ grain, respectively. The higher dietary grain contents in the earlier studies must have resulted in a larger amount of fermentable carbohydrate reaching the large intestine. This would increase fermentation, bacterial growth, and LPS shedding in this part of the digestive tract (Li et al., $2012 \mathrm{~b}$ ). Also, ad libitum feeding was adopted by Li et al. (2012a,b,c), whereas the calves in the present study were limited to
DMI of $2.25 \%$ of BW. This could have further reduced the availability of substrates for the bacteria flora in the large intestine of the calves and resulted in overall lower growth rate of bacteria and lower LPS releasing.

The concentrations of LPS in plasma were below the detection limit of $0.14 \mathrm{EU} / \mathrm{mL}$ for all treatments (Table 7). The absence of LPS in peripheral blood plasma was in agreement with findings in previous studies where moderate- (Khafipour et al., 2009b) or high-grain diets (Gozho et al., 2007; Li et al., 2012b) were fed. However, an increase in the concentration of LPS in peripheral blood during a grain-based SARA challenge reported by Khafipour et al. (2009a) was accompanied by lower rumen $\mathrm{pH}$ and higher LPS concentration in rumen digesta. Compared with our study, the higher rumen acidity and ruminal LPS concentration in the earlier studies would have increased the risk of translocation of LPS out of the rumen (Emmanuel et al., 2008; Plaizier et al., 2012). In the parallel study of Schurmann (2013), barrier function of the rumen epithelium decreased when the duration of grain feeding increased. However, Schurmann (2013) determined this barrier function by measuring tissue conductance and the flux of mannitol through epithelial tissue in Ussing chambers. Mannitol is a small molecule compared with LPS. Hence, the

Table 5. Effects of the duration of feeding a moderate-grain diet on the butyrate concentration $(\mathrm{m} M)$ of digesta in the intestines of calves

\begin{tabular}{|c|c|c|c|c|c|c|c|c|c|}
\hline \multirow[b]{2}{*}{ Compartment } & \multicolumn{5}{|c|}{ Treatment $^{1}$} & \multirow[b]{2}{*}{$\mathrm{SE}$} & \multicolumn{3}{|c|}{ Contrast $^{2}$} \\
\hline & $\mathrm{CON}$ & MG3 & MG7 & MG14 & MG21 & & $\mathrm{L}$ & Q & $\mathrm{C}$ \\
\hline Jejunum & 0.41 & 0.43 & 0.42 & 0.43 & 0.39 & 0.06 & 0.81 & 0.70 & 0.98 \\
\hline Ileum & 0.65 & 0.75 & 0.59 & 0.70 & 0.74 & 0.14 & 0.68 & 0.71 & 0.94 \\
\hline Cecum & 3.90 & 4.72 & 5.64 & 5.98 & 6.35 & 0.68 & 0.01 & 0.33 & 0.67 \\
\hline Colon & 3.18 & 5.02 & 6.47 & 5.60 & 6.23 & 0.66 & 0.01 & 0.06 & 0.07 \\
\hline Rectum & 2.58 & 6.28 & 8.64 & 6.84 & 9.73 & 1.20 & $<0.01$ & 0.19 & 0.02 \\
\hline
\end{tabular}

${ }^{1}$ Control (CON) calves received $91.5 \%$ chopped hay and $8.5 \%$ vitamin-mineral supplement. Calves assigned to MG3, MG7, MG14, and MG21 received a high-energy (moderate-grain) diet consisting of $41.5 \%$ barley grain, $50 \%$ chopped hay, and $8.5 \%$ vitamin-mineral supplement for 3, 7, 14, and $21 \mathrm{~d}$, respectively.

${ }^{2}$ Contrast patterns: $\mathrm{L}=$ linear, $\mathrm{Q}=$ quadratic, $\mathrm{C}=$ cubic. 
Table 6. Effects of the duration of feeding a moderate-grain diet on the ammonia nitrogen concentration (mg/ $\mathrm{dL}$ ) of digesta in the intestines of calves

\begin{tabular}{|c|c|c|c|c|c|c|c|c|c|}
\hline \multirow[b]{2}{*}{ Compartment } & \multicolumn{5}{|c|}{ Treatment $^{1}$} & \multirow[b]{2}{*}{$\mathrm{SE}$} & \multicolumn{3}{|c|}{ Contrast $^{2}$} \\
\hline & $\mathrm{CON}$ & MG3 & MG7 & MG14 & MG21 & & $\mathrm{L}$ & $\mathrm{Q}$ & $\mathrm{C}$ \\
\hline Rumen & 14.86 & 13.72 & 19.70 & 20.62 & 13.58 & 1.66 & 0.71 & $<0.01$ & 0.15 \\
\hline Jejunum & 11.48 & 11.90 & 7.34 & 9.28 & 9.90 & 1.63 & 0.40 & 0.18 & 0.77 \\
\hline Ileum & 6.76 & 5.94 & 5.56 & 7.34 & 5.28 & 0.80 & 0.58 & 0.61 & 0.06 \\
\hline Cecum & 8.20 & 6.60 & 6.22 & 7.32 & 6.16 & 0.59 & 0.14 & 0.46 & 0.03 \\
\hline Colon & 5.64 & 4.20 & 4.74 & 5.18 & 4.46 & 0.39 & 0.38 & 0.75 & 0.03 \\
\hline Rectum & 4.72 & 3.86 & 4.06 & 4.12 & 3.66 & 0.33 & 0.07 & 0.67 & 0.09 \\
\hline
\end{tabular}

${ }^{1}$ Control (CON) calves received $91.5 \%$ chopped hay and $8.5 \%$ vitamin-mineral supplement. Calves assigned to MG3, MG7, MG14, and MG21 received a high-energy (moderate-grain) diet consisting of $41.5 \%$ barley grain, $50 \%$ chopped hay, and $8.5 \%$ vitamin-mineral supplement for $3,7,14$, and $21 \mathrm{~d}$, respectively.

${ }^{2}$ Contrast patterns: $\mathrm{L}=$ linear, $\mathrm{Q}=$ quadratic, $\mathrm{C}=$ cubic.

paracellular permeability of the rumen epithelium for mannitol may be greater than that for LPS, and changes in this permeability (and therefore barrier function) for mannitol may not reflect similar changes in the barrier function for LPS. Another reason for the absence of LPS in peripheral blood could be that the acidity and LPS concentration of digesta in the large intestine in our study were lower than that in the studies by Li et al. (2012b). As high acidity and a high concentration of LPS of digesta in the large intestine may pose a greater risk for translocation of LPS than that of digesta in the rumen (Plaizier et al. 2008; Li et al., 2012b), differences in the conditions of hindgut digesta between our study and that of Li et al. (2012b) may explain why LPS was only detected in peripheral blood in the earlier study. The absence of LPS in peripheral blood must not be interpreted to indicate the total absence of translocation of LPS out of the digestive tract, as the liver rapidly detoxifies LPS in portal blood and peripheral blood (Andersen et al., 1994; Munford, 2005). Hence, translocation of LPS from the digestive tract may increase LPS in peripheral blood only once the LPS-detoxifying capacity of the liver has been exceeded.
Increased concentrations of LBP, Hp, and SAA in bovine peripheral blood are often detected during grain-induced SARA, regardless of an increase in LPS in peripheral blood (Khafipour et al., 2009b; Li et al., 2012a,b). These increases in acute phase proteins indicate systemic inflammation in cattle. Nonetheless, the concentrations of LBP, Hp, and SAA in peripheral blood remained unchanged in our study. This further proves that a moderate increase in LPS in ruminal and intestinal digesta may not reach the threshold for translocation and triggering systemic inflammation (Zebeli et al., 2012).

\section{CONCLUSIONS}

This study is the first to report a longitudinal change in the concentrations of LPS in the digesta throughout the bovine digestive tract. The greatest concentration of LPS in the digesta was observed in the rumen and ileum, followed by the large intestine, whereas the lowest concentration was detected in the jejunum. An increase in ruminal LPS was detected after switching from a forage-based diet to a MG diet. In contrast to

Table 7. Effects of the duration of feeding a moderate-grain diet on concentrations of acute phase proteins serum amyloid A (SAA), haptoglobin (Hp), and LPS-binding protein (LBP), and endotoxic LPS in peripheral blood plasma of calves

\begin{tabular}{|c|c|c|c|c|c|c|c|c|c|}
\hline \multirow[b]{2}{*}{ Item } & \multicolumn{5}{|c|}{ Treatment $^{1}$} & \multirow[b]{2}{*}{$\mathrm{SE}$} & \multicolumn{3}{|c|}{ Contrast $^{2}$} \\
\hline & $\mathrm{CON}$ & MG3 & MG7 & MG14 & MG21 & & $\mathrm{L}$ & $\mathrm{Q}$ & $\mathrm{C}$ \\
\hline $\mathrm{SAA}, \mathrm{mg} / \mathrm{L}$ & 59.9 & 56.2 & 42.2 & 49.2 & 53.1 & 12.5 & 0.78 & 0.46 & 0.79 \\
\hline $\mathrm{Hp}, \mathrm{mg} / \mathrm{L}$ & 104.1 & 101.6 & 103.5 & 83.7 & 106.8 & 15.8 & 0.79 & 0.37 & 0.34 \\
\hline $\mathrm{LBP}, \mathrm{mg} / \mathrm{L}$ & 4.5 & 5.7 & 4.3 & 2.9 & 3.8 & 1.4 & 0.41 & 0.71 & 0.42 \\
\hline LPS, EU/mL & $\mathrm{ND}^{3}$ & ND & ND & ND & ND & & & & \\
\hline
\end{tabular}

${ }^{1}$ Control (CON) calves received $91.5 \%$ chopped hay and $8.5 \%$ vitamin-mineral supplement. Calves assigned to MG3, MG7, MG14, and MG21 received a high-energy (moderate-grain) diet consisting of $41.5 \%$ barley grain, $50 \%$ chopped hay, and $8.5 \%$ vitamin-mineral supplement for $3,7,14$, and $21 \mathrm{~d}$, respectively.

${ }^{2}$ Contrast patterns: $\mathrm{L}=$ linear, $\mathrm{Q}=$ quadratic, $\mathrm{C}=$ cubic.

${ }^{3} \mathrm{ND}=$ not detectable (i.e., $<0.14 \mathrm{EU} / \mathrm{mL}$ ). 
the change in ruminal LPS, a linear reduction of LPS in jejunal digesta indicated that the capacity of LPS degradation before the jejunum and in the proximal jejunum increased when the calves were fed the MG diet for an extended period. The high LPS concentration in ileal digesta and its drastic reduction from the ileum to the cecum warrant further research on the role of the ileum in host defense against gut-derived endotoxins. However, the absence of, and increase in, acute phase proteins, such as LBP, SAA, and Hp, as well as the undetectable concentration of LPS in peripheral blood indicated that no systemic inflammation occurred, regardless of the increases in LPS in the digestive tract of calves.

\section{ACKNOWLEDGMENTS}

This study was supported by a grant from the Natural Sciences and Engineering Research Council of Canada (NSERC). We thank Paula Azevedo (Department of Animal Science, University of Manitoba, Winnipeg, Canada) for her technical assistance.

\section{REFERENCES}

Andersen, P. H., M. Hesselholt, and N. Jarlov. 1994. Endotoxin and arachidonic acid metabolites in portal, hepatic and arterial blood of cattle with acute ruminal acidosis. Acta Vet. Scand. 35:223-234.

Bhandari, S. K., K. H. Ominski, K. M. Wittenberg, and J. C. Plaizier. 2007. Effects of chop length of alfalfa and corn silage on milk production and rumen fermentation of dairy cows. J. Dairy Sci. 90:2355-2366.

CCAC. 1993. Guide to the Care and Use of Experimental Animals. Vol. 1. E. D. Olfert, B. M. Cross, and A. A. McWilliam, ed. Canadian Council on Animal Care (CCAC), Ottawa, ON, Canada.

Chin, A. C., A. N. Flynn, J. P. Fedwick, and A. G. Buret. 2006. The role of caspase-3 703 in lipopolysaccharide-mediated disruption of intestinal epithelial tight 704 junctions. Can. J. Physiol. Pharmacol. 84:1043-1050.

Dofferhoff, A. S., J. H. Nijland, H. G. de Vries-Hospers, P. O. Mulder, J. Weits, and V. J. Bom. 1991. Effects of different types and combinations of antimicrobial agents on endotoxin release from gram-negative bacteria: an in vitro and in vivo study. Scand. J. Infect. Dis. 23:745-754.

Emmanuel, D. G., S. M. Dunn, and B. N. Ametaj. 2008. Feeding high proportions of barley grain stimulates an inflammatory response in dairy cows. J. Dairy Sci. 91:606-614.

Goris, H., F. de Boer, and D. van der Waaij. 1988. Kinetics of endotoxin release by gram-negative bacteria in the intestinal tract of mice during oral administration of bacitracin and during in vitro growth. Scand. J. Infect. Dis. 20:213-219.

Gozho, G. N., D. O. Krause, and J. C. Plaizier. 2007. Ruminal lipopolysaccharide concentration and inflammatory response during grain-induced subacute ruminal acidosis in dairy cows. J. Dairy Sci. 90:856-866.

Gozho, G. N., J. C. Plaizier, D. O. Krause, A. D. Kennedy, and K. M. Wittenberg. 2005. Subacute ruminal acidosis induces ruminal lipopolysaccharide endotoxin release and triggers an inflammatory response. J. Dairy Sci. 88:1399-1403.

Hampton, R. Y., D. T. Golenbock, M. Penman, M. Krieger, and C. R. Raetz. 1991. Recognition and plasma clearance of endotoxin by scavenger receptors. Nature 352:342-344.
Hurley, J. C. 1995. Endotoxemia: Methods of detection and clinical correlates. Clin. Microbiol. Rev. 8:268-292.

Khafipour, E., D. O. Krause, and J. C. Plaizier. 2009a. Alfalfa pelletinduced subacute ruminal acidosis in dairy cows increases bacterial endotoxin in the rumen without causing inflammation. J. Dairy Sci. 92:1712-1724.

Khafipour, E., D. O. Krause, and J. C. Plaizier. 2009b. A grain-based subacute ruminal acidosis challenge causes translocation of lipopolysaccharide and triggers inflammation. J. Dairy Sci. 92:10601070.

Khafipour, E., S. Li, J. C. Plaizier, and D. O. Krause. 2009c. Rumen microbiome composition determined using two nutritional models of subacute ruminal acidosis. Appl. Environ. Microbiol. $75: 7115-7124$

Lallès, J. P. 2010. Intestinal alkaline phosphatase: Multiple biological roles in maintenance of intestinal homeostasis and modulation by diet. Nutr. Rev. 68:323-332.

Le Huerou, I., P. Guilloteau, C. Wicker, A. Mouats, J. A. Chayvialle, C. Bernard, J. Burton, R. Toullec, and A. Puigserver. 1992. Activity distribution of seven digestive enzymes along small intestine in calves during development and weaning. Dig. Dis. Sci. 37:40-46.

Li, S., G. N. Gozho, N. Gakhar, E. Khafipour, D. O. Krause, and J. C. Plaizier. 2012a. Evaluation of diagnostic measures for subacute ruminal acidosis in dairy cows. Can. J. Anim. Sci. 92:353-364.

Li, S., E. Khafipour, D. O. Krause, A. Kroeker, J. C. RodriguezLecompte, G. N. Gozho, and J. C. Plaizier. 2012b. Effects of subacute ruminal acidosis challenges on fermentation and endotoxins in the rumen and hindgut of dairy cows. J. Dairy Sci. 95:294-303.

Li, S., E. Tesfaye, H. Khazanehei, M. Scott, I. Yoon, E. Khafipour, and J. C. Plaizier. 2012c. Impact of feeding yeast culture under normal and SARA conditions in lactating dairy cows. J. Anim. Sci. 90(Suppl. 3):485. (Abstr.)

Lodemann, U., and H. Martens. 2006. Effects of diet and osmotic pressure on $\mathrm{Na}+$ transport and tissue conductance of sheep isolated rumen epithelium. Exp. Physiol. 91:539-550.

Maki, L. R., and K. Picard. 1965. Normal intestinal flora of cattle fed high-roughage rations. J. Bacteriol. 89:1244-1249.

Mani, V., A. J. Harris, A. F. Keating, T. E. Weber, J. C. Dekkers, and N. K. Gabler. 2013. Intestinal integrity, endotoxin transport and detoxification in pigs divergently selected for residual feed intake. J. Anim. Sci. 91:2141-2150.

Mani, V., T. E. Weber, L. H. Baumgard, and N. K. Gabler. 2012. Growth and Development Symposium: Endotoxin, inflammation, and intestinal function in livestock. J. Anim. Sci. 90:1452-1465.

Munford, R. S. 2005. Detoxifying endotoxin: Time, place and person. J. Endotoxin Res. 11:69-84.

Nagaraja, T. G., E. E. Bartley, L. R. Fina, and H. D. Anthony. 1978. Relationship of rumen gram-negative bacteria and free endotoxin to lactic acidosis in cattle. J. Anim. Sci. 47:1329-1337.

Nagaraja, T. G., E. E. Bartley, L. R. Fina, H. D. Anthony, and R. M. Bechtle. 1978. Evidence of endotoxins in the rumen bacteria of cattle fed hay or grain. J. Anim. Sci. 47:226-234.

Nagaraja, T. G., and E. C. Titgemeyer. 2007. Ruminal acidosis in beef cattle: The current microbiological and nutritional outlook. J. Dairy Sci. 90(E-Suppl. 1):E17-E38.

Neutra, M. R., A. Frey, and J. P. Kraehenbuhl. 1996. Epithelial M cells: Gateways for mucosal infection and immunization. Cell $86: 345-348$.

Novozamsky, I., R. Van Eck, J. C. H. Schouwenburgand, and F. Walinga. 1974. Total nitrogen determination in plant material by means of the indole-phenol blue method. Neth. J. Agric. Sci. 22:3-5.

Penner, G. B., M. Oba, G. Gabel, and J. R. Aschenbach. 2010. A single mild episode of subacute ruminal acidosis does not affect ruminal barrier function in the short term. J. Dairy Sci. 93:4838-4845.

Plaizier, J. C., E. Khafipour, S. Li, G. N. Gozho, and D. O. Krause. 2012. Subacute ruminal acidosis (SARA), endotoxins and health consequences. Vet. J. 172:9-21.

Plaizier, J. C., D. O. Krause, G. N. Gozho, and B. W. McBride. 2008. Subacute ruminal acidosis in dairy cows: The physiological causes, incidence and consequences. Vet. J. 176:21-31. 
Poelstra, K., W. W. Bakker, P. A. Klok, M. J. Hardonk, and D. K. Meijer. 1997. A physiologic function for alkaline phosphatase: Endotoxin detoxification. Lab. Invest. 76:319-327.

Rescigno, M., G. Rotta, B. Valzasina, and P. Ricciardi-Castagnoli. 2001. Dendritic cells shuttle microbes across gut epithelial monolayers. Immunobiology 204:572-581.

Ribeiro, M. M., X. Xu, D. Klein, N. S. Kenyon, C. Ricordi, M. S. Felipe, and R. L. Pastori. 2010. Endotoxin deactivation by transient acidification. Cell Transplant. 19:1047-1054.

Schurmann, B. L. 2013. Short-term adaptation of the rumen epithelium involves functional changes in sodium and short-chain fatty acid transport. MSc thesis. Department of Animal and Poultry Science. University of Saskatchewan, Saskatoon, SK, Canada.

Tajima, K., S. Arai, K. Ogata, T. Nagamine, H. Matsui, M. Nakamura, R. I. Aminov, and Y. Benno. 2000. Rumen bacterial com- munity transition during adaptation to high-grain diet. Anaerobe 6:273-284.

Wells, J. E., and J. B. Russell. 1996a. Why do many ruminal bacteria die and lyse so quickly? J. Dairy Sci. 79:1487-1495.

Wells, J. E., and J. B. Russell. 1996b. The effect of growth and starvation on the lysis of the ruminal cellulolytic bacterium Fibrobacter succinogenes. Appl. Environ. Microbiol. 62:1342-1346.

Zebeli, Q., and B. N. Ametaj. 2009. Relationships between rumen lipopolysaccharide and mediators of inflammatory response with milk fat production and efficiency in dairy cows. J. Dairy Sci. 92:3800-3809.

Zebeli, Q., B. U. Metzler-Zebeli, and B. N. Ametaj. 2012. Meta-analysis reveals threshold level of rapidly fermentable dietary concentrate that triggers systemic inflammation in cattle. J. Dairy Sci. 95:2662-2672. 